\title{
V. On finding the longitude by lunar observations
}

\section{Mr. Henry Meikle}

To cite this article: Mr. Henry Meikle (1819) V. On finding the longitude by lunar observations , Philosophical Magazine Series 1, 54:255, 34-39, DOI: 10.1080/14786441908652178

To link to this article: http://dx.doi.org/10.1080/14786441908652178

曲 Published online: 29 Jul 2009.

Submit your article to this journal

III Article views: 2

Q View related articles $₫$ 
and apparently stitched: doubting that there could be such stitching, I undid a part, and discovered that they perforated the surface, and then stuck in the fine shreds of leather. The curious will observe that the patterns of the stool cushion are all produced by paring the surface. They make their soldiers' belts and pouches out of elephant or pig skin ornamented with red shells.

Of their carpenters' work the stool is a fair specimen, being carved out of a solid piece of a wood called zesso, white, soft, and bearing a high polish; it is first soalied in water. They sell such a stool for about three shillings; in Accra or Fantee it would fetch twenty. The umbrella is even more curious; the bird is cut almost equal to turning, and the whole is so supple that it may be turned inside out. This (only a child's umbrella) is a model of the large canopies I have described in the procession; I gave a piece of cloth value twenty shillings for it. The sanko or guitar is also neatly made, and the chasteness and Etruscan character of the carving is very surprising. The surface of the wood is first charred in the fire, and then carved deep enough to disclose the original white in the stripes or lines of the patterns.

Numbers of workmen are employed in breaking, rounding and boring the snail shells, as big as a turkey's egg generally, and sometimes as large as a conch. They are first broken into numerous pieces; then chipped round, the size of a slecve-button, and afterwards bored with a bow and iron style fixed in a piece of wood. Lastly, they are strung and extended in rows on a log of wood, and rubbed with a soft and blueish gray stone and water, until they become perfectly round.

Their pine-apple thread is very strong, and is made from the fineness of a hair to the thickness of whip-cord; it bleaches to a beautiful whiteness, and would answer for sewing any strong materials; but when muslin is stitched with it, it is liable to be cut from the harshness. The women frequently join their cloths and ornament their handkerchiefs with a zigzag pattern worked with unravelled silks of different colours. The fetish case is a specimen of their needle-work in the manner of chain stitch.

\section{On finding the Longitude by Lunar Observations. By Mr. Henty Meikle.}

\section{To Mr. Tilloch.}

Sir, - The problem of finding the longitude by the lunar observations has long and justly been regarded as an interesting subject. '\% accomplish this desirable end, various methods of reducing the lunar distances have been proposed with different degrees of success. But while methods very different agree in 
bringing out the same result, it may also be remarked, that many methods apparently different are essentially the same; the seeming difference arising only from the endless variety of forms under which the quantities may be analytically expresserl. Hence many have fancied themselves the inventors of new methods, who are little, if in any degree, entitled to the name.

The pretensions to accuracy are likewise of very different degrees : some of these being also of the imaginary kind; for some of the greatest efforts to attain exactness are frequently productive of greater errors than those they were intended to remove. Thus, where perfection is aimed at, an allowance is made on the sun and moon's altitudes for the effect of refraction in diminishing their.vertical semidiameters, without considering that the centre is seldom the apparent place of the angular point of the spherical triangle; - sometimes also an allowance is made for the contraction of that semidiameter which is to be applied to the distance. This, as we shall afterwards see, is likewise an elaborate way of creating new errors.

But at any rate, however great may be the distortion of the disk by refraction, this does not in the least affect the true altitude of the centre, when the other corrections are properly applied ; for, if to the observed altitude of the limb, we first apply the refraction, \&r.. we get the true altitude of the limb; and if to this, the horizontal semidiameter be afterwards applied, it gives tile true altitude of the centre absolutely free from such an error. This, though hinted at by different authors, seems to be little, if at all, adopted in practice ; for in books of navigation it is customary first to apply the semidiameter to the observed altitude of the limb, as if that would accurately give the apparent altitude of the centre, and then with this altitude to take out the corrections.

Some sort of respect, it is true, may in this way be paid to the centre of the luminary; but it is only a needless source of error, which might be avoided without any additional labour. It would hence appear, that the sun and moon's " true altitudes" when about $7^{\circ}$ are, in addition to other inaccuracies, subjected to an unnecessary error of $18^{\prime \prime}$ by the usual careless way of working. But, as we shall afterwards see, this is only half the extent to which the error may go with the apparent altitude. It is in vain that we expect accuracy even from the best observers and instruments, if such needless errors are persevered in.

Although the common way of first applying the semidiameter does not accurately give the apparent altitude of the centre; yet in some cases it gives that of a point which is very near to that point of the vertical diameter through which the continuation of the arc representing the apparent distance would pass, especially 
when sensibly affected by the distortion of the disk. Now the position of this point is evidently of more importance than that of the centre itself; because the centre is not necessarily the apparent place of the angular point of the triangle.

Suppose the vertical semidiameter of the moon to be shortened by the small space $A B$. Then if we take the distance of the moon's limb at $E$, from an object which lies in the direction $\mathrm{EF}$. this arc E F will be perpendicular to the limb at $\mathrm{E}$, and if produced, will cut the vertical diameter at some proint $\mathrm{D}$, which is below the cenare $C$, by a space nearly equal A B. For the upper part of the disk will not sensibly differ from a circle whose radius is equal the

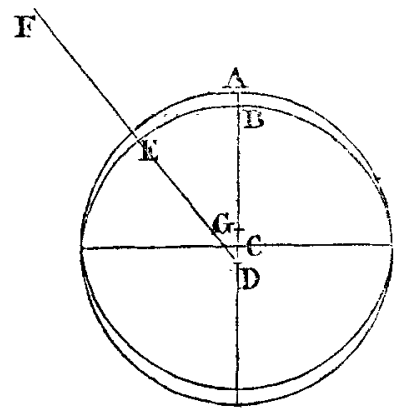
semidiameter parallel to the horizon, unless the altitude be very small. If, therefore, we have observed the altitude of the upper limb, the place of $D$ (not the centre) is found by subtracting the augmented semidiameter. But when the distane has been taken from a part of the disk on a different side of the diameter which is parallel to the horizon from the limb whose altitude has been observed, then this method fails; for in the present, case, had the altitude of the lower limb been observed, and the semidiameter added, it would have given the altitude of a point $G$ as much above the centre as it ought to be below. When this takes place, recourse must be bad to a table answering to the space DG. From this it is evident, that when the apparent altitude of an angular proint of the spherical triangle is about $7^{\circ}$, it nay sometimes, in the comınon way of working, be erronenus by $36^{\prime \prime}$; and even in the method hitherto used for remedying this evil, the ernor will rarely be less than $18^{\prime \prime}$ at the altitude of $7^{\circ}$. But both are much more considerable when the altitude is smaller.

The method referred to, for correcting the altitudes for the distontion of the disk, by a table answering to the diminution of the vertical semidiameter, is thus productive of an evil little inferior to the one it was intended to remove; for although by it the true alkitude of the centre were obtainer, and also its apparent altitude; yet, as bas been: remarked, the :entre is sejdom the point from which the apparent distance should be reckoned; so that what is gained in getting the true altitude of the centre is just lost. in departing from the point from which the distance should be taken; and to which, as we have:already seen, the commen way of working often:makes a much nearer approach.

With regard to the line D.E, which some learned authors have 
been pleased to consider as shortened by refraction, the mistake has no doubt arisen from the old established habit of always estimating the apparent distance from the centre. But if we suppose the disk to be elliptical *, then it may be shown, that if from any point of either axis of an ellipsis but the centre, a straight line be drawn perpendieular to the curve, - this line, sometimes called the normal, is greater of less than half the other axis, according as the point was taken in the conjugate or transverse axis. D E is, therefore, al ways greater thas the greatest semiriameter; so that it is obvionsly much safer just to account it equal the augmented setmidiameter than kess.

I do not mean to insinzate that $I$ have put this subject beyond the possibility of improvement; or that there may not be defects in the above way of considering it. My object is merely to make a nearer approach to accuracy with as little additional labour as possible. The method which I would therefore recommend when the distance and altitude have both bcen meastred from parts of the limb which are either both above or both below the centre-is, first, to find the true altitude of the limb; to which the true or horizontal semidiameter being afterwards applied gives the true altitude of the centre. Next to the observed altitude of the limb apply the " agunented semidiameter," which will give the place of D; and ther with these eompute the true distanee as ustual. But when the distance and al titude have been observed from different sides of the dianneter parallel to the horizon, it will be necessary that the correction contained in several boeks fot the contraction of the whole vertical dianeter be subtracted from the-senidiameten which is to be applied to the apparentaltitude of the limb in order to get the place of $\mathbf{D}$.

It may be proper to antieipate an objection whieh might be brought against this method-that when the anghe at the sun or moon is a right angle, the centre is the angular point of the triangle; and the above rule would then make the altitutei erteneous by half the contraction. This camot be denied : but it is no less obvious, that a smrall alteration on the altitude at a right anghe will have no sersible effect on the distance, which is the main thing to be attended to. If greater accuracy were required, a careful determisation of the figure of the -disk would probably point out the econstruetion of a table answering more correctly to DG, and which might be applieable to different angles informed at the luminaries. A table could likewise be formed which would give the excess of DE above the :semidiameter for different angles

* The figure of the sun or moon when rear the horizon will more nearly consist of two semi-ellipses having the transverse axis common to both; but the semi-conjugate axis of the upper half greater than that of the lower: It is easy to see, that the above theorem applies on this supposition also. 
and altitudes. But this is a degree of nicety ton laborious for common practice.

It will probably be alleged that much has been said about a small correction,-that of removing the effects of the contraction of the sun and moon's disk. But if this degree of accuracy may be attained with little or no additional labour, I think it ought not to be neglected; and the more especially as there are probably abundance of remaining inaccuracies not so easily dislodged from the lunar distances. Besides, I do not consider an error of seven or eight minutes of longitude unworthy of avoiding, when it can be done so easily; and a much greater error may sometimes be produced by neglecting the quantity under cousideration. Toward the equator, where the errors depending on the figure of the earth vanish, this one may still have its maximum effect on the lunar distance.

Among other vague things so abundant in books of navigation, it is customary to say - that " the limb of the Hadley's quadrant contains only $45^{\circ}$ or the eighth part of the circle; but that by reason of the double reflexion the angle is doubled." It would, indeed, be difficult to give a more insignificant description of this instrument; for it is easy to show, that the doubling (or rather halving) is completely effected by the first reflexion: the second serving no other purpose than that of giving the rays a more convenient direction. It might perhaps have at least some meaning, to say - " that the limb contains only $45^{\circ}$, for by reason of the reflexion of the index-mirror, the instrument only gives half the observed angle." But our authors on navigation are generally so well trained to follow in the old-beaten, track, that they run little risk of waudering into any improvement.

It is a common popular doctrine, that parallax operntes only in a vertical direction. But if this were true, it would make the moon appear of an oval figure, which, as is easily shown, cannot be the case; for it is obvious, that if the moon be spherical she must appear circular, let the observer go where he will, except so far as depends on the intervening medium. The difference of the parallaxes for any two diametrically opposite limbs, constitutes what is called the augmentation of the diameter.

Another thing which claims strong reprobation, is, the method of finding the latitude by a table of "difference of altitude of polestar and pole." This mothod is always erroneous, unless the latitude be near to 0 ; or, when the polestar is in the meridiana case where the aid of such a helpless table is not wanted.

In this method it is iberally supposed, that the altitnde of the polestar when six hours distant from the meridian is the same as that of the pole. This, however, is no where true but at the equator; and the reason is obvious: for in any other case when the 
star is six hours from the meridian, its zenith distance, which is less than $90^{\circ}$, being the hypothenuse of a right-angled spherical triangle, is therefore gieater than the zenith distance of the pole, which is only a side of that triangle.

But another grand fault is - that it makes no provision for the rapid change of polar distance to which this star is subject. Had it no other fault, this alone would render such a table vague enough in the course of a very few years. In some very respectable and scientific works a table of this sort is given, in which the polar distance of the polestar (involved in the whole table) is erroneous by $4{ }^{\prime} 6$ at the time of publication; and as the error increases nearly one minute in three years, it is not difficult to perceive what confidence ought to be put in such tables.

All the errors and delusions I have noticed are more or less indebted to the original system of copying the same things over and over again, withont ever inquiring whether they have a good foundation, or indeed any foundation at all. Such is the contented and unsuspecting disposition of modern authors, that they can safely take each other's word for things which in less enlightened times wonld have required a demonstration. Suspicion, the very bane of society, becomes an exalted virtue when applied to science. I am, sir,

\section{Your most obedient servant,}

Hent Meikle.

\section{On Aërolites.}

\section{To Mr. Tilloch.}

SIR, - I He very curious question of aërolites has lately been introduced into your pages by MM. Capuel Lofft and Acton; and though I seldom indulge in sjeculative opinions on scientific subjects, being more desirous of confining myself to a simple detail of experiments and facts, I am induced to digress a little from that line in the present instance.

You may remember that in one of my former papers I adverted to a meteoric stone which fell at Pulrose in the Isle of Man. The evidence which I collected seemed to attest the fact, and place it beyond a doubt; and yet its physical characters of extreme levity and scoriaceous texture, seemed to, impose a doubt upon its identity with those stony masses which have at different times visited the earth; and this comparisnil, coupled with an examination of those aërolites which I had the opportunity of seeing in many museums on the continent, did not tend to unhinge that doubt.

In this uncertainty of mind I turned over the leaves of the C. 4 